\title{
EDITH STEIN Y MARÍA ZAMBRANO: MIRADAS ANTE LO SAGRADO Julieta Lizaola*
}

Llegó con tres heridas la del amor, la de la muerte, la de la vida.

Miguel Hernández

autoras que pueda ser considerado como un mismo sentido, algo que

La presente propuesta de lectura ha sido realizada bajo la idea de introducirnos a las preocupaciones que compartieron dos de las pensadoras más singulares del siglo XX; ambas vivieron dentro de un mismo período histórico en una Europa que se desmoronaba y donde los principios renacentistas e ilustrados eran arrojados al abismo. La pregunta que surge inevitable es qué hay en ambas

*Departamento Académico de Estudios Generales, ITAM. se dirija en una misma dirección. Lo primero es su contemporaneidad. El haber participado de la misma historia aunque una fuera criada en el catolicismo español y otra en el judaísmo ortodoxo alemán. Ambas se iniciaron a la vida marcadas por la guerra, ambas compartieron las repercusiones del fascismo -la exclusión y el exilio-, el sentido de lo sagrado y la influencia de la mística de San Juan de la Cruz.

El horizonte histórico que se abrió ante ellas orilló sus pensamientos hacia la reflexión cultural 
y su evidente destrucción espiritual. ¿Cuál era la dignidad del hombre contemporáneo, dónde había quedado la promesa de libertad, es decir, de plenitud? El totalitarismo es un fenómeno que toma forma en la primera mitad del siglo Xx y ante el cual surge en ambas pensadoras un impulso intelectual dirigido a encontrar respuesta frente al fenómeno que ha dado lugar a la ignominia contemporánea que no cesa.

Zambrano realizará un recorrido por el pensamiento occidental; siguiendo su arqueología encontrará la semilla de una razón insuficiente, de una razón que siendo su origen la obtención del conocimiento por medio de la violencia, no duda al fundamentar una construcción social empobrecedora del espíritu del hombre moderno. Stein manifestará su profunda preocupación por la ya casi exigua capacidad de los hombres de reconocerse unos en otros.

Zambrano y Stein perciben su momento histórico como la manifestación de un quiebre cultural al que es necesario interrogar. Si el hombre y su necesidad de encontrar su lugar en el cosmos ya no permanece en el centro de sus cuestiones vitales, sino que esta necesidad ha sido vaciada de contenido, desplazada por formas de sometimiento, manipulación y violencia, la cuestión a reflexionar es cómo revertir esta devastación que se cierne sobre el mundo.

Ambas pensadoras consideran que su papel ante esto no puede ser otro que el de la búsqueda. El intelectual tiene un compromiso social que deriva de su posibilidad de observar el mundo. Así, desde diferentes perspectivas, es suya la obligación de señalar y aliviar la humillación del hombre contemporáneo. La filosofía es transformación de lo real en verdadero, dice Zambrano, es hacer verdad la transformación de los hechos en el orden y conexión del pensamiento; en la medida en que tal transformación se cumpla aparecerá el sistema o el fragmento del sistema. La filosofía es entonces una acción. La acción fundamental de transformar lo oculto, lo ambiguo, en claro, en diáfano, en lo transitable como tiempo y como espacio, lo manifiesto y manifestable a todos los hombres; las consecuencias de esta acción son el paso, como en la caverna, de la oscuridad a la luz, de la tierra al mundo, del tribalismo a la sociedad de personas, de la historia sacrificial a la historia ética.

El mundo se ha constituido en un orden donde el tejido contra la libertad humana ha ido tomando cuerpo hasta convertirse en abierta intencionalidad política y manifestándose en francas guerras de exterminio, negando implícitamente las 
vías de la política y depositando una inconmensurable carga de sufrimiento en las sociedades contemporáneas: la intolerancia, el racismo, la reedición de nuevas tiranías. Y desde ahí, desde el sufrimiento del otro y por lo tanto mío y nuestro, es desde donde las pensadoras europeas se manifestarán como antagonistas del estuche vaciado de espíritu que advirtió Max Weber. La modernidad se les aparece como un proyecto agotado éticamente, donde el dolor y el sufrimiento son los elementos que enfrentan la destrucción moral del yo- racional y el fracaso de los sueños del racionalismo. Reconciliar vida y razón será, desde diferentes puntos de vista, el objetivo filosófico y vivencial de Zambrano y Stein: la experiencia de lo sagrado será el elemento unificador.

Desde la perspectiva de Zambrano es necesario poner sobre la mesa un conflicto central: la discusión cultural y su fundamento religioso. $\mathrm{Su}$ planteamiento filosófico pasa por reabrir áreas de diálogo sobre problemas que aún no hemos podido comprender; en este caso en específico, el repensar el lugar de lo sagrado en la filosofía moderna y contemporánea bajo intención de ahondar en el análisis del dolor cultural del hombre actual.

La búsqueda de explicación a la incapacidad de reconocimiento entre los hombres contemporáneos es algo más que una vocación filosófica para Stein. La disolución moral del hombre se alza como una nueva voluntad política y es esta intencionalidad negadora la que es preciso conocer para desarticularla. La soledad, en el sentido de una pobre convivencia social y en la cual viven las nuevas masas, les niega capacidad de identificación, de organización, de empatía, de reconocerse unos en otros, de sentirse unos en otros.

Por lo descrito anteriormente, podemos advertir que la similitud que encontramos en ambas autoras no es sólo su apreciación y análisis de su contemporaneidad histórica sino que además podemos observar un punto de coincidencia fundamental: el reconocimiento del sufrimiento como el elemento que impulsa en ambas la consideración de decisiones sustanciales. En una se acrecentará el impulso filosófico, en otra éste se irá haciendo uno con su religiosidad. No olvidemos que la experiencia de lo sagrado será la savia que alimente las dos vías.

Lo sagrado, como sabemos, es un tema resbaladizo y borrascoso sobre todo desde el lado de la filosofía. La sociología y la antropología contemporáneas lo han tratado con más eficacia: han logrado esclarecer las funciones sociales que realiza y las características culturales que ha pro- 
piciado; la psicología, a su vez, nos ha ofrecido su perspectiva que en términos generales guarda relación con la necesidad de compensación humana. La filosofía moderna y contemporánea han sido más desconfiadas en su propia fundamentación a la hora de dar una definición sobre su carácter y sentido.

\section{II}

Lo sagrado, como tema de reflexión en el pensamiento de María Zambrano, se inicia frente a este vaciamiento de la existencia, su consecuente empobrecimiento de la realidad y la constitución de la nada en la conciencia contemporánea. La nada como un límite histórico de la conciencia moderna, donde la angustia no sólo cuestiona la finitud del ser sino principalmente la estructura de la cultura moderna ya agotada. El camino que nos conduce al tema de lo sagrado en Zambrano, se realiza mediante la necesidad filosófica de entender los procesos de secularización moderna, procesos en los que se persigue la fundamentación laica de la vida. Ante este fenómeno la autora pone el dedo en la llaga: no hay secularización, hay transformación, metáforas de lo divino.

Para Zambrano éste es un conflicto fundamental que le lleva a proble- matizar la naturaleza de lo sagrado como una vía de acceso a la que ella considera su pregunta más importante: el ser del hombre y su construcción cultural.

Es corriente caracterizar a nuestra época como irreligiosa. Más acertado sería descubrir las religiones que la pueblan clandestinamente. Clandestinamente porque tienen por carácter que sus fieles no las aceptan como tales; sus creyentes no quieren del todo creer en ellas. Las sirven a pesar de sí mismos, sin responsabilidad [...] Obscuras religiones y dioses, que necesitan de toda la debilidad de la conciencia actual para vivir. Dioses a los que el hombre despierto, en la plenitud de sus facultades, se avergüenza de servir. $^{1}$

Recordemos que la referencia que Zambrano busca en el fenómeno de lo sagrado es encontrar en él una comprensión cultural; hay en su pensamiento la intención de ir a las raíces del encuentro de lo numinoso como acceso al desciframiento de la edificación cultural. Y esto desde la perspectiva de la reconstrucción de la experiencia anímica de lo sagrado, que a su vez permitiría explicar la constitución ontológica y axiológi-

${ }^{1}$ María Zambrano, "El freudismo", en Revista filosófica Malacitana, 1991, Universidad de Málaga, vol. IV, p. 16. 
ca del hombre contemporáneo. En suma: una mirada de reconstrucción cultural que persigue la fenomenología de lo divino para darnos su comprehensión sobre ésta, es un desesperado intento del ser humano con todo lo otro que le asedia y le atormenta. $^{2}$

Es pertinente señalar que la autora no desarrolla sus observaciones desde la profesión de una fe o una creencia religiosa, tampoco lo hace defendiendo o privilegiando una postura en contra de alguna perspectiva religiosa. Lo hace desde la mirada de la filosofía de la cultura, que busca dar una explicación fenomenológica y hermenéutica de lo sagrado. Recordemos que su libro $E l$ hombre y lo divino inicia con la siguiente afirmación: Toda cultura depende de la calidad de sus dioses. De tal forma, la realidad es identificada con lo sagrado ya que sólo éste puede surgir; la realidad no un atributo que unas cosas poseen y otras no, sino algo anterior a las cosa mismas; en suma, la realidad se corresponde con lo sagrado conformando la matriz de donde nacen las divinidades. Ir al encuentro de lo sagrado es ir al encuentro de la plenitud de la realidad y -algo muy importante- establecer la

${ }^{2}$ Chantall Maillard, "Ideas para una fenomenología de lo divino", en Anthropos. Revista de documentación cientifica de la cultura, Barcelona $\mathrm{n}^{\mathrm{o}} 70 / 71$, p. 123. posibilidad de una forma de trato con ella. Lo originario es la experiencia de la carencia, de la no plenitud, del no pertenecer, de la orfandad. La realidad se hace visible por medio de lo sagrado.

Los dioses han nacido porque el espacio de lo sagrado fue posible en el hombre tras la experiencia inicial de la oscuridad, postula la filósofa española, siendo así una relación alcanzada, lograda, con un gran esfuerzo cultural. La manifestación de los dioses corresponde, entonces, a algo ineludible en el hombre: recordemos que toda cultura, según este planteamiento, "depende de la configuración que lo divino haya tomado frente al hombre". ${ }^{3}$

Es importante seguir el planteamiento de la 'imposibilidad de vivir sin dioses', que advierte Zambrano. La razón iluminista había dejado como herencia el creer que se encontraba en capacidad de descifrar todos los enigmas. La razón convertida en racionalismo fue excluyendo, como parte de la vida, todo aquello que no podía tener bajo control. Para Zambrano superar el racionalismo significa lograr un nuevo paso filosófico: observar la manifestación de lo sagrado en lo divino, advertir, así, qué implica que lo divino haya adquirido una claridad tal que permi-

${ }^{3}$ María Zambrano, El hombre y lo divino, 1992, Madrid, Siruela, p. 29. 
ta a la razón verlo, tener su imagen y poder descifrarlo como expresión de lo sagrado.

Solamente hemos de dejar apuntado que lo que el hombre moviliza para engendrar la objetividad es religioso, como lo que hay en la base y fundamento de todo nuestro apego a la realidad y a la transformación que la hemos de padecer para crear nuestro mundo. ${ }^{4}$

Este apunte que hace la autora es de esencial importancia, pues en estas líneas deja sentada su concepción de cultura, de historia y, lo que en este caso nos atañe más de cerca, de filosofía. Nos parece importante poner de relieve la no escisión de disciplinas que ello implica y reiterar la idea de que el fundamento original del conocimiento es religioso. Por ello mismo, Zambrano contempla que debe darse una forma de acceso a esta dimensión para poder elaborar desde ahí el pensamiento filosófico.

Sobre esta escondida fuerza religiosa, sobre esta esperanza que engendra nuestras creencias, creencias en que se afirma el orden del mundo, en que la realidad obscura ha adquirido transparencia, permanencia y sentido, surge la filosofía. Y filosofía es razón, lo fue al

${ }^{4}$ María Zambrano, Hacia un saber sobre el alma, 2000, Madrid, Alianza Editorial, p. 98. menos en su comienzo. $\mathrm{Y}$ éste es el drama. ${ }^{5}$

Estas concepciones de cultura, historia y filosofía contienen un punto de unión: el actuar piadoso, el actuar amoroso que nos acerca a lo otro, que nos permite pensar y conocer con amplitud al no tener como principio el juzgar que algo es real por ser racional. Este nuevo pensar será dirigido a rescatar las formas de lo divino que expresan lo sagrado.

Filosofía y Religión se vienen disputando la realización de las esperanzas humanas [...] La Religión, es verdad, ha sido la tradicional depositaria de las esperanzas humanas, de las más imprescindibles, es decir, de las más verdaderas y entrañables. Pero así como hay filosofías que han querido realizar por la razón el delirio, también hay religiones que han tomado a su cargo desengañar al hombre, imbuirle resignación, adormirle en su desesperación. Y es que Filosofía y Religión no se distinguen del todo, por ser la una depositaria de la esperanza y la otra su amargo despertar. ${ }^{6}$

La filosofía ha podido salir de su afán racionalista, o filosofía del sujeto, gracias a andar de nuevo los caminos que le permiten recordar

${ }^{5} \mathrm{Ibid}$.
${ }^{6} \mathrm{Ibid}$. 
que la filosofía es diálogo, y que para ello se necesita del otro; recordar que es en el hablar que logramos la transparencia del pensamiento. Se trata de una lectura diferente de la historia y la cultura que tiene como piedra angular el ir a esa parte de la razón moderna que ha sido negada, donde no hay tiempo ni espacio para la interioridad, eso que permite construir y descubrir lo que Zambrano denomina persona.

Es lo sagrado una vía de conocimiento donde la cultura, y no la religión, es la receptora del conocimiento y de los aprendizajes que se han ido desprendiendo del sentir religioso. Así, el conocimiento de la vida del alma se transforma en una metafísica de la interioridad donde se resguardan sentimientos, ideas, deseos, sueños, creaciones, razones, renuncias, exilios, sinrazón, padecer; conjunción de esperanzas. Y esto es lo que encierra la tesis que hemos derivado del análisis del pensamiento de la autora: la recuperación filosófica del alma como unidad del ser permitiendo su integridad. Lo anterior nos permite comprender su crítica al racionalismo y la superación de éste en el desciframiento de lo sagrado que se manifiesta en las diversas formas de lo divino. Desde aquí podemos afirmar que lo sagrado, fondo y sustento de la vida, es en lo que Zambrano funda al hombre y su historia.

\section{III}

Edith Stein desde muy joven se formuló una pregunta sustancial para su vida: ¿Cómo servir a la humanidad? Su visión fue clara: buscando una respuesta a la existencia del hombre. En ella podemos observar la vocación filosófica y la búsqueda ética como sentido de vida. Durante largo tiempo le acompañará esta preocupación, acrecentándose en intensidad ante el rostro que toman los acontecimientos políticos en Europa. El cuestionarse sobre la mejor vía para servir a la humanidad se ve reformulado cuando elige para su tesis doctoral el tema de la empatía, es decir, la capacidad de conectar con el otro desde el otro. Su inquietud intelectual inicial le conducirá a la fenomenología husserliana. Su crisis interna sufrirá un momento definitivo cuando se encuentre con la lectura de Teresa de Ávila. De este suceso obtendrá un sentido que le permitirá definir su vida espiritual: ser instrumento de Dios. Su actividad filosófica se transformará entonces en parte de su apostolado.

Cuando llega Hitler al poder su inquietud se ahonda $\mathrm{y}$, coincidiendo con los primeros años del nazismo, 
se transforma en monja carmelita adoptando el nombre de Teresa Benedicta de la Cruz. Su nuevo nombre da cuenta de lo que fue conformando el sustento de su vida religiosa: el interceder con el sufrimiento voluntario en favor de la salvación humana, ayudar a cargar la cruz de Cristo; para ello, trata de hacer compatible su actividad intelectual con un elemento para ella fundamental, la oración.

Lo sagrado, desde la perspectiva de Edith Stein, guarda relación intrínseca con la fe. Su conversión al catolicismo, después de una crisis de desmoronamiento de la concepción judía, quiere dar cuenta del carácter de unificación que perseguirá entre su necesidad intelectual y su sentimiento religioso. Su tarea, tanto de búsqueda filosófica como de praxis, pasan por la idea de servir a Dios. En específico, de ser instrumento de Él. ¿Instrumento para qué? Para que a través de ella se pueda cumplir una voluntad que desea la salvación en general del hombre y en específico de liberarlo del peso del pecado y, por lo mismo, del sufrimiento como expresión de vida. Stein, al igual que Zambrano, se duele profundamente del dolor del hombre contemporáneo; el reconocer la fragilidad espiritual de su época es lo que la lleva a elegir la vía por medio de la cual pueda ser, de forma más definida, servidora de Cristo. Serán dos los caminos principales que se trazará inicialmente: la oración como guía y fundamento y el desarrollo de sus trabajos filosóficos. La experiencia de lo sagrado será un impulso que acrecentará su fe y su actuar cristiano, es decir, de ayuda a la redención del mundo. Para ello elegirá la via crucis como camino propio, cuyo sentido será acompañar a Cristo. Cargar con él la Cruz, aligerar en algo el terrible peso de la expiación, de la obediencia al Padre en su designio de redimir al hombre gracias a la liberación de la esclavitud del pecado; aliviar el sufrimiento del mundo tomando para ella una porción, desviándolo de las entrañas del hombre y de la espalda de Cristo. La cuestión central es el alivio, la liberación, la consolación del sufrimiento ¿Cómo lograrlo?

Su propósito será unir el pensamiento de los grandes doctores de la Iglesia, de la escolástica, de la mística, con la filosofía moderna. Así, encontramos en su escritura un diálogo continuo con Tomás de Aquino, Agustín de Hipona, Dionisio Areopagita, Juan de la Cruz, entre otros. Es en Fray Juan de la Cruz donde deseo detenerme; no sólo por el hecho de que los dos carmelitas encontraron como quicio o paradigma de su vida la cruz de Cristo, sino también porque su figura es un punto 
de coincidencia en las pensadoras que nos ocupan: María Zambrano y Edith Stein. Ambas admiraron al místico, el poeta y el hombre que fue Juan de la Cruz y, de tal manera, que las dos filósofas lo harán parte de sus reflexiones y, curiosamente, en sus últimos escritos ambas lo tendrán presente. Edith Stein, como es sabido, escribió su último libro, La ciencia de la Cruz, inspirada en él. Zambrano, también en su último libro, incluye un ensayo donde lo considera uno de Los Bienaventurados. ${ }^{7}$ Recordemos que para la filósofa española la Noche también significa la posibilidad que antecede al renacimiento de nuestro ser. La Noche oscura $^{8}$ es el núcleo donde se fusionan las visiones de Juan de la Cruz, Edith Stein y María Zambrano. Es el espacio que nos permite la experiencia de los sagrado, el encuentro con lo más hondo y verdadero que nos vive: el encuentro del Amado con la Amada para Juan de la Cruz, la mirada que se detiene en la huella para inhabitarse con Dios para Stein, la entrada al claro del bosque donde la palabra sagrada podrá salir a nuestro encuentro para Zambrano.

7 Zambrano María, Los Bienaventurados, 1995, Madrid, Siruela.

${ }^{8}$ San Juan de la Cruz, Obra completa, 1999 , Madrid, Alianza Editorial.

\section{IV}

Lo que ocurre en el alma, su anhelo de transparencia, y lo que le ocurre al pensamiento filosófico, su afán de transparencia y transformación, no se quedan en la vida meramente subjetiva como esencias inmateriales sino que se objetivan, se realizan. Si se busca la claridad, la luz, es para que la vida humana sea una fuente cristalina, un surtidor que nos permita vislumbrar nuestra verdad, nuestro sentido. Esto es lo que más fatigosamente ha querido realizar el desarrollo cultural de Occidente: hacer que la vida del hombre tenga un sentido esclarecido. ¿Cómo se logra encarnar lo que anhelamos?

Para ambas filósofas la poesía y la mística de Juan de la Cruz son un elemento central en sus vidas. San Juan, que había nacido casi cinco siglos antes que ellas, resultaba una fuente de inspiración: en una, filosófica; en la otra, de acción congruente con su experiencia religiosa. El santo poeta será observado detenidamente por ambas. $\mathrm{Su}$ poesía, fruto de sus arrobamientos religiosos, en tanto que producto del amor, logra la objetividad de algo, mas no su destrucción como ocurre con los deseos una vez saciados. La negación de sus apetitos -la aparente crueldad con que niega su alma hasta lograr desaparecerla- en el necesario 
proceso de negación y vaciamiento para dejar un espacio sin nada que pueda ser habitado por el Amado. La noche oscura es la búsqueda de las almas, no sólo de su encuentro con el Amado, sino también de sus íntimas verdades.

Para Zambrano la cruz de San Juan es claridad lograda, diáfano conocimiento del alma que gracias al actuar del hombre permite que su experiencia mística sea un camino de vida. San Juan no llama a la muerte como Teresa de Jesús, no desea morir, no ve en ella salida ni trascendencia. Traspasar instancias de la vida y llegar a otras posibilidades - situadas en el límite entre la vida y la muerte- sin destruir la vida es factible y lo es gracias a la poesía. A ese poder que sin violencia accede a otra forma de obtener el saber:

Este saber no sabiendo

Es de tan alto poder

Que los sabios arguyendo

Jamás lo pueden vencer

Que no llega su saber a no entender entendiendo

Toda ciencia trascendiendo ${ }^{9}$

San Juan de la Cruz logra más que el conocer, el ser. Si abandona la vida, si se sumerge en el ascetismo, es porque para vivir necesita atravesar ciertos umbrales. Embebido por

\footnotetext{
${ }^{9}$ Ibid., p. 264.
}

la vida quiere nada porque lo quiere todo. Sabe que otra vida es posible en este mundo donde se gusta la realidad más recóndita de las cosas. Sin embargo, no abandona la vida, realiza la paradoja: alejándose se adentra más en ella: Entremos más adentro en la espesura.

La idea como concepto, el conocimiento como resultado sólo racional, cuando se logra, accede a la objetividad, es decir, logra dibujar al ser no en las entrañas, como lo hace el poeta, sino sólo en la mente. La poesía, que corresponde al territorio de la carne, logra en San Juan la objetividad; y si lo logra es gracias al amor, al agotar hasta lo último la posibilidad de las cosas y de la vida. Ello por cumplir con plenitud los apetitos de su alma, cumplir con su hambre devoradora de ser. San Juan se aparece ante los ojos de María Zambrano como el poeta y el místico, como el bienaventurado, que ha logrado transitar de la noche oscura a la más clara mística.

En Edith Stein la cruz de San Juan parece un ejemplo a seguir: el no claudicar, no ceder ante poderes humanos que desean la denigración. La cruz de San Juan es una imagen de vida de un verdadero cristiano: el que vive el amor detenido en los hechos que se suceden en su vida. Para ella el camino también será el amor. Aceptará su cruz, la de 
Teresa Benedicta de la Cruz, como el cumplimiento de la voluntad de Dios y sobre todo con la intención y la voluntad clara de ofrendar su vida. Lo supo desde joven, lo supo cuando ejerció la pedagogía y se planteó que si ésta tenía un sentido, éste sería el de llevar a los alumnos hacia aquello que debían ser como personas, el profesor como un medio que ayuda a elaborar la estructura de las personas que tiene frente a sí. Lo advirtió también cuando planteó que la relación entre personas requería del conocimiento mutuo, es decir, de la empatía. Y aún más: cumplió su ofrenda al aceptar su partida a Polonia, a los campos de exterminio, como una posibilidad de cumplir su deseo vital, el de hacer algo por la humanidad, mirando hacia Dios. En el poder de la cruz puedes estar en todos los frentes, en todos los lugares de aflicción, a todas partes te llevará tu amor misericordioso, el amor del corazón divino derrama sangre que alivia, santifica y salva. ${ }^{10}$ Edith Stein será un cordero en el holocausto. Como un acto de honda fe se cumplirá no el sacrifico sino lo que ella consideró la ofrenda verdadera de amor a Cristo.

Es necesario detenerse en la preocupación por la persona, tema

${ }^{10}$ Edith Stein, "Exaltación de la Cruz", en Escritos Espirituales, 1999, Madrid, Biblioteca de autores cristianos, p. 150. coincidente en las reflexiones de las pensadoras que nos ocupan, y que para ambas es imprescindible. La española observa que el mundo contemporáneo contiene un elemento de raíz, desde el cual nuevas formas de poder legitiman y legalizan el que no existan personas, y aún más, que se les destruya. Nuevo precepto político de dominación donde las personas ceden su lugar frente a las masas, insertas en una historia que no las reconoce. Ante esto es necesaria una nueva cultura que cobije a los seres y su existencia, en su autonomía y su interdependencia; una nueva cultura basada en el amor como orden axiomático que nos permita identificar el genocidio cultural y físico, para negarlo, para rechazarlo o para librarnos de la posibilidad del ser y de la historia atados al arquetipo originario del sacrificio, el cual nos señala que no hemos modificado nuestra referencia inicial con el mundo. Zambrano se rebela contra la situación anterior. Quiere que rompamos la estructura conceptual en que hemos edificado nuestro actuar ético, que abandonemos la condición que establece intercambiar muerte por vida. En su pensamiento, el sacrificio como intermediario no tiene justificación. Oponernos a los que piden víctimas en aras de un orden civilizatorio se vuelve una acción ética fundamental. La persona 
es la posibilidad del ser humano, de ser, y esto no se puede olvidar: la necesidad de pasar de una historia sacrificial a una historia ética.

Es necesario que lo luminoso del conocimiento, como una fuente cristalina, siga brotando del alma humana. Es necesario realizar el viaje que Zambrano pide a la propia filosofía: que nos deje observar cómo se ha ido desprendiendo la luz de las entrañas humanas. ${ }^{11}$ Cuando Zambrano afirma que la razón poética es el camino está diciendo que adentrarse en lo divino es encontrar el sentimiento que de ahí nace transformado en palabra. Este viaje implica a la piedad; a la posibilidad de mirar y aceptar lo que se mira: lo otro y el trato con lo otro. La esperanza de Zambrano echa raíz en que el hombre es una criatura, entre otras cosas, capaz de amar.

Finalmente, concluimos recogiendo lo que ambas autoras, seres de dulce condición - tal como nombraba María Zambrano a los pitagóricosnos dejaron como ofrenda: observar el alma humana como morada de la experiencia de lo sagrado.

${ }^{11}$ Adolfo Castañón, Fulgor de María Zambrano, 2002, México, Ediciones sin nombre, p.43. 